\title{
Order effects of high-intensity intermittent and strength exercise on lipoprotein profile
}

\author{
Tiego Aparecido Diniz ${ }^{1,3}$ - Daniela Sayuri Inoue ${ }^{3}$ Fabricio Eduardo Rossi ${ }^{2,3}$. \\ Valéria Leme Gonçalves Panissa ${ }^{4} \cdot$ Paula Alves Monteiro $^{2,3} \cdot$ Fabio Santos Lira $^{3}$
}

Received: 19 April 2016/ Accepted: 26 June 2016/Published online: 11 July 2016

(C) Springer-Verlag Italia 2016

\begin{abstract}
Purpose To compare the effects of the order of concurrent exercise (endurance plus strength or strength plus endurance) on lipoprotein profiles in men.

Methods After the evaluation of maximum strength (one repetition maximum-1RM) in the half-squat and of aerobic fitness (maximal velocity in treadmill incremental test), 11 physically active male subjects underwent two randomized sessions composed of four sets of half-squat
\end{abstract}

Fabio Santos Lira

fabiolira@fct.unesp.br

Tiego Aparecido Diniz

tiegodiniz@gmail.com

Daniela Sayuri Inoue

dsinoue@gmail.com

Fabricio Eduardo Rossi

rossifabricio@yahoo.com.br

Valéria Leme Gonçalves Panissa

valeriapanissa@gmail.com

Paula Alves Monteiro

paulinha_1003@hotmail.com

1 Department of Cell and Developmental Biology, Institute of Biomedical Sciences, University of São Paulo, São Paulo, Brazil

2 Department of Physical Education, Center of Studies and Laboratory of Evaluation and Prescription of Motor Activities (CELAPAM), Sao Paulo State University (UNESP), 19060-900 Presidente Prudente, SP, Brazil

3 Exercise and Immunometabolism Research Group, Department of Physical Education, Sao Paulo State University (UNESP), Rua Roberto Simonsen, 305, 19060-900 Presidente Prudente, SP, Brazil

4 School of Physical Education and Sport, University of São Paulo, São Paulo, SP, Brazil strength exercises until exhaustion (at $80 \%$ of 1RM) and a $5-\mathrm{km}$ run high-intensity intermittent exercise (1:1 min at $V_{\max }$ ), performed in different orders: (1) strength plus run (S-A) and inverse order, and run plus strength (A-S). Blood samples were collected before and immediately after the first exercise (Post-1) and after the second exercise (Post-2) in the intra-session sequence. Serum was analyzed for total cholesterol (TC) and its ratio, HDL-c and LDL-c, and triacylglycerol (TAG).

Results There were effects of condition for TC, LDL-c, and TC/HDL, with greater values in the AS than SA $(p<0.001$ for all). For the delta analysis, there was an interaction effect for TAG, with greater delta-1 S-A than delta-1 A-S $(p=0.035)$, and higher delta-1 S-A than delta2 S-A $(p=0.001)$; for LDL-c, with higher delta-1 S-A values than delta- 2 S-A $(p=0.010)$; and for TC, with higher delta-1 S-A values than delta-2 S-A $(p=0.038)$.

Conclusion We conclude that there are no differences between the order of acute high-intensity intermittent run plus strength exercises regarding modulation of the lipoprotein profile in healthy, physically active men.

Keywords Aerobic exercise - Strength exercise · Lipoprotein

\section{Introduction}

Sedentary behaviour is recognized as one of the most powerful risk factors for metabolic diseases, such as type 2 diabetes, hypertension and high levels of low-density lipoprotein cholesterol (LDL-c) and low high-density lipoprotein cholesterol (HDL-c), which are linked to the development of atherosclerosis [1], this being one of the leading causes of death worldwide [2]. 
Regular exercise decreases lipid-related atherosclerotic risk factors [3], and both acute and chronic exercises can reduce triacylglycerol concentrations by $15-50 \%$ [4]. Tsekouras et al. [5] observed that a single and prolonged bout of moderate-intensity walking (90-120 min at $60 \%$ of peak oxygen consumption) lowers fasting plasma very low-density lipoprotein (VLDL) concentrations in the morning following the workout.

On the other hand, high-intensity interval exercise (HIIE), which is performed using lower volume and higher intensity (i.e., $\leq 10 \mathrm{~min}$ of intense exercise), has been a method of interest in improving metabolic markers $[6,7]$ when compared to traditional continuous endurance exercise (vigorous intensity 77-95\% of maximal heart rate or 64-90 \% of $\mathrm{VO}_{2 \max }$ ) [8]. In the same way, acute or chronic strength exercise can promote an improvement in the lipid profile, especially regarding a decrease in LDL-c concentrations $[9,10]$.

The previous research has shown that the endurance plus strength exercise order induces significant improvements in lipids and lipoproteins; however, this sequence increases residual fatigue and decreases available substrate, which together can hamper the adaptations from strength exercise [11-13]. In a systematic review, comparing different training modes with different intensities, Tambalis et al. [10] emphasized that endurance plus strength training could be an option of interest in improving cardiovascular health. However, studies that have verified the effects of HIIE plus strength exercise on hypolipidemia are scarce. We believe that combining HIIE with strength exercises could be a noteworthy option for improving lipoprotein response, since endurance training increases the oxidation of lipids in skeletal muscle and the liver, while strength training increases muscle anabolism [14].

To the best of our knowledge, no studies have aimed to verify the best order of concurrent training (endurance plus strength or strength plus endurance) for improving lipid profiles. Thus, the main objective of this study was to compare the effects of the order of concurrent exercises (endurance plus strength or inverse order) on lipoprotein profiles in healthy young adults.

\section{Materials and methods}

\section{Subjects}

Eleven physically active males with strength and endurance training experience ( $>6$ months) participated in this study. Participants were free from health problems and/or neuromuscular disorders that could affect their ability to complete the study protocol. Participants took part voluntarily in the study after being informed of the procedures, risks, and benefits and signed an informed consent form. This study was approved by the Ethics Committee (number 792.369).

\section{Procedures}

The subjects completed six experimental sessions separated by at least $72 \mathrm{~h}$. All sessions were preceded by a 5 min warm-up at $50 \%$ of the maximal endurance running test $\left(V_{\max }\right)$. During the first session, anthropometric and $V_{\max }$ measurements were performed on a treadmill. During the second and third sessions, the participants were submitted to familiarization of the one repetition maximum (1RM) test, and during the fourth session, the $1 R M$ test was performed. Two more experimental sessions were applied in randomized order: (a) strength plus run exercise in the following order $(\mathrm{S}-\mathrm{A})$ : one session in which participants performed four sets of the half-squat strength exercise until exhaustion (at $80 \%$ 1RM) followed by a $5-\mathrm{km}$ high-intensity intermittent run exercise (1:1 min at $\left.\mathrm{vVO}_{2} \max \right)$ and (b) run plus strength exercise in the following sequence (A-S): a 5-km high-intensity intermittent run exercise $\left(1: 1 \mathrm{~min}\right.$ at $\left.\mathrm{vVO}_{2} \mathrm{max}\right)$ followed by four sets of the half-squat strength exercise until exhaustion (at $80 \% 1 \mathrm{RM}$ ). There was a $10 \mathrm{~min}$ recovery interval between the run and strength exercises. All tests were performed at the same time of day for each subject. The subjects were instructed to abstain from any strenuous exercise for at least $48 \mathrm{~h}$ prior to each testing session and were encouraged to maintain their nutrition and hydration routines.

\section{Maximal endurance running test}

The subjects performed an incremental test to volitional exhaustion. The initial treadmill (Inbramed, MASTER CI, Brazil) speed was set at $8.0 \mathrm{~km} \mathrm{~h}^{-1}$ and was increased by $1 \mathrm{~km} \mathrm{~h}^{-1}$ per 2-min stage until the participant could no longer continue. $V_{\max }$ reached in the test was defined as the maximal intensity attained. When the subject was not able to finish the 1-min stage, the speed was expressed according to the permanence time in the final stage, determined as the following: $V_{\max }=$ velocity of the penultimate stage $+[$ (time, in seconds, remained in the final stage multiplied by $\left.1 \mathrm{~km} \mathrm{~h}^{-1}\right) / 60 \mathrm{~s}$ [ [15].

\section{Maximum dynamic strength test}

To determine half-squat maximum dynamic strength, the one maximum repetition test (1RM) was performed on a Smith machine (Ipiranga ${ }^{\circledR}$, São Paulo, Brazil). Following the warm-up, participants were allowed up to five attempts to achieve the 1RM load (i.e., maximum weight 
that could be lifted once with proper technique), with a 3-5 min interval between attempts, as per standard procedures [16].

For better control of the 1RM test procedures, the body position and feet placement of each participant in the halfsquat exercise were recorded and reproduced throughout the study. In addition, an adjustable-height wooden seat was placed behind the participant to keep the bar displacement and knee angle $\left(\sim 90^{\circ}\right)$ constant in each halfsquat repetition.

\section{Concurrent exercise}

After warm-up, the participants were allowed a 2-min interval prior to begin the exercise session. The endurance exercise consisted of a $5-\mathrm{km}$ intermittent run on the treadmill (1 min at $V_{\max }$ followed by 1-min passive recovery). During HIIE, the treadmill remained in operation throughout the session, and at the end of each bout, the participants were asked to jump off the treadmill. In addition, the participants could ask the distance covered, and how many bouts remained, etc. at any time. Next, the subjects performed four sets of maximum repetitions of the half-squat exercise at $80 \%$ of $1 \mathrm{RM}$ on a Smith machine. Each set of strength exercises was followed by a 2-min passive rest interval. The maximum number of repetitions performed was recorded, and the total volume was calculated (repetitions $\times$ weight lifted).

\section{Blood sampling and analyses}

Blood samples were collected at rest, and immediately after each exercise condition, as illustrated in Fig. 1.

The blood samples $(20 \mathrm{ml})$ were immediately allocated into two $5 \mathrm{ml}$ vacutainer tubes (Becton-Dickinson, Juiz de
Fora, MG, Brazil) containing EDTA for plasma separation and into two $5 \mathrm{ml}$ dry vacutainer tubes for serum separation. The tubes were centrifuged at $3000 \mathrm{rpm}$ for $15 \mathrm{~min}$ at $4{ }^{\circ} \mathrm{C}$, and plasma and serum samples were stored at $-20{ }^{\circ} \mathrm{C}$ until analysis. Glucose, total cholesterol (TC) and its ratio, HDL-c and LDL-c, and triacylglycerol (TAG) were assessed using commercial kits (Labtest ${ }^{\circledR}$, São Paulo, Brazil). Only serum was used.

\section{Statistical analysis}

The data were analyzed using a Statistical Analysis System (Version 9.2; SAS Institute, Cary, NC) and are presented as means and standard deviation. Linear mixed models were used to compare the blood variables in different conditions across time (condition $\times$ time). The Tukey post hoc was conducted if a significant difference was found. Statistical significance was set at $p<0.05$. Delta 1 was calculated by post-1-prevalues, and delta 2 was calculated by post-2-post-1 values. Standardized effect sizes (d) were also calculated using Coheńs equations [17] with the following threshold values: $<0.2$-trivial; $>0.2$ and $<0.6-$ small; $>0.6$ and $<1.2$ moderate; $>1.2$ and $<2.0$ - large; $>2.0 \quad$ and $<4.0$-very large; $<4.0$ —nearly perfect [18].

\section{Results}

Table 1 presents the mean values of age, body composition, $V_{\max }$, and 1RM of all subjects at the baseline of this study. In the S-A condition, subjects performed a greater number of repetitions and higher total volume than A-S condition subjects $(54 \pm 45$ vs. $43 \pm 12$ and $7265 \pm 2323$ vs. $5794 \pm 1846 \mathrm{~kg}$, respectively). However, only six subjects finished the $5-\mathrm{km}$ run in the S-A condition.

\section{A - S Condition}

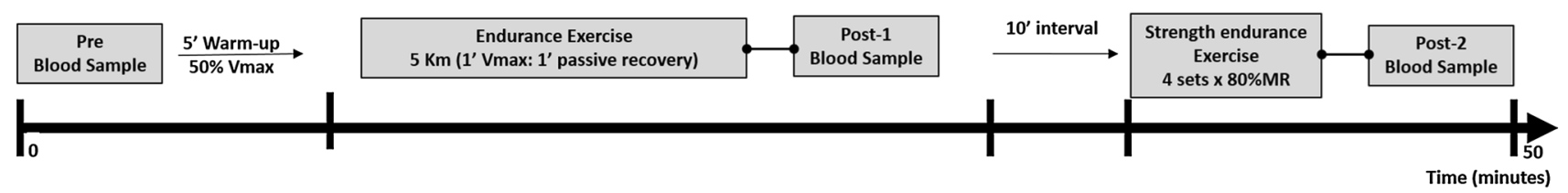

\section{S - A Condition}

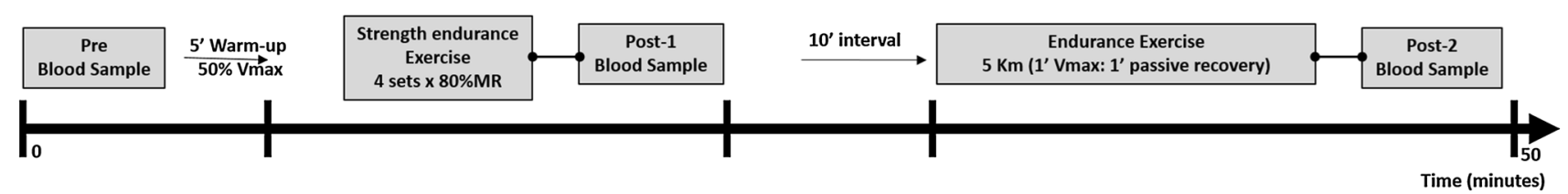

Fig. 1 Blood sample flowchart 
Table 1 Characteristic of the sample $(n=11)$

\begin{tabular}{lc}
\hline Variable & \multicolumn{1}{l}{ Sample } \\
\hline Age (years) & $26.28 \pm 4.27$ \\
Body weight $(\mathrm{kg})$ & $73.43 \pm 7.59$ \\
Height $(\mathrm{cm})$ & $174.19 \pm 5.95$ \\
BMI $\left(\mathrm{kg} \mathrm{m}^{-1}\right)$ & $24.18 \pm 1.92$ \\
Body lean mass $(\mathrm{kg})$ & $58.32 \pm 7.32$ \\
Body fat $(\mathrm{kg})$ & $14.67 \pm 5.72$ \\
Body Fat $(\%)$ & $19.89 \pm 7.24$ \\
One maximum repetition $(\mathrm{kg})$ & $169.91 \pm 36.85$ \\
Maximum velocity $\left(\mathrm{km} \mathrm{h}^{-1}\right)$ & $14.31 \pm 1.69$ \\
\hline
\end{tabular}

Table 2 shows the comparison of the lipoprotein profiles between the S-A and A-S conditions at the pre, post-1, and post-2 sampling moments.

For total TC, there was a main effect for condition $\left(F_{1,45.3}=19.88 ; p<0.001\right)$ with lower values in the S-A than A-S $[p<0.001 ; d=0.701$ (moderate)]. Similarly, for TC/HDL, there was a main effect for condition $\left(F_{1,41.4}=8.49 ; p=0.005\right)$ with lower values in the S-A than A-S $[p<0.001 ; d=0.469$ (small)]. The LDL concentrations also presented a main effect for condition $\left(F_{1,20.68}=8.49 ; p<0.001\right)$ with lower values in the S-A than A-S $[p<0.001 ; d=0.569$ (small)].

However, for the delta analysis of TAG, there was an interaction effect $\left(F_{1,66.8}=4.00 ; p<0.001\right)$, with greater delta-1 S-A than delta-1 A-S $[p=0.035 ; d=0.827$ (moderate)], and higher delta-1 S-A than delta-2 S-A [ $p=0.001 ; d=0.366$ (small)]. For the delta analysis of LDL, there was an interaction effect $\left(F_{1,59.9}=11.42\right.$; $p=0.001)$, with higher values in delta-1 S-A than delta-2 S-A $[p=0.010 ; d=0.180$ (trivial) $]$, and a tendency to higher values in delta-2 A-S than delta-2 S-A $[p=0.068$ (small)]. Finally, for the delta analysis of TC, there was an interaction effect $\left(F_{1,66.3}=6.69 ; p=0.011\right)$, with higher values in delta-1 S-A than delta-2 S-A $[p=0.038$; $d=1.80$ (large)].

\section{Discussion}

The uniqueness of this study is the investigation of the sequence of concurrent exercise in the modulation of hepatic lipid metabolism among healthy, trained men. We
Table 2 Comparison between S-A and A-S conditions at the pre, post-1, and pos- 2 moments on the lipoprotein profile

\begin{tabular}{|c|c|c|c|c|}
\hline Variables & S-A condition & $\Delta$ & A-S condition & $\Delta$ \\
\hline \multicolumn{5}{|c|}{ TAG (mg/dl) } \\
\hline Pre & $143.8 \pm 44.2$ & & $158.8 \pm 45.4$ & \\
\hline Post-1 & $158.4 \pm 43.4$ & $11.3 \pm 12.4^{\mathrm{b}, \mathrm{c}}$ & $158.9 \pm 48.4$ & $0.01 \pm 11.9$ \\
\hline Post-2 & $148.7 \pm 44.2$ & $-4.0 \pm 5.3$ & $165.3 \pm 52.6$ & $4.6 \pm 13.4$ \\
\hline \multicolumn{5}{|c|}{$\mathrm{TC}(\mathrm{mg} / \mathrm{dl})^{\mathrm{a}}$} \\
\hline Pre & $160.8 \pm 18.8$ & & $182.6 \pm 35.0$ & \\
\hline Post-1 & $175.0 \pm 21.1$ & $9.0 \pm 7.1^{\mathrm{b}}$ & $187.9 \pm 36.3$ & $3.0 \pm 5.7$ \\
\hline Post-2 & $171.7 \pm 37.6$ & $-4.6 \pm 7.9$ & $195.5 \pm 40.2$ & $5.8 \pm 24.4$ \\
\hline \multicolumn{5}{|c|}{ HDL (mg/dl) } \\
\hline Pre & $41.7 \pm 11.4$ & & $38.9 \pm 7.6$ & \\
\hline Post-1 & $45.2 \pm 7.2$ & $11.9 \pm 18.2$ & $44.9 \pm 9.9$ & $15.6 \pm 13.5$ \\
\hline Post-2 & $50.8 \pm 8.9$ & $16.7 \pm 29.5$ & $49.1 \pm 17.2$ & $13.7 \pm 30.7$ \\
\hline \multicolumn{5}{|c|}{$\operatorname{LDL}(\mathrm{mg} / \mathrm{dl})^{\mathrm{a}}$} \\
\hline Pre & $149.7 \pm 31.4$ & & $179.0 \pm 45.8$ & \\
\hline Post-1 & $163.7 \pm 2.7$ & $10.6 \pm 11.6^{\mathrm{c}}$ & $177.6 \pm 49.1$ & $-0.9 \pm 7.7$ \\
\hline Post-2 & $155.0 \pm 54.3$ & $-10.4 \pm 14.6$ & $182.3 \pm 52.1$ & $6.2 \pm 28.6$ \\
\hline \multicolumn{5}{|c|}{$\mathrm{TC} / \mathrm{HDL}(\mathrm{mg} / \mathrm{dl})^{\mathrm{a}}$} \\
\hline Pre & $4.2 \pm 1.3$ & & $5.0 \pm 1.4$ & \\
\hline Post-1 & $4.0 \pm 0.8$ & $0.15 \pm 19.1$ & $4.5 \pm 1.4$ & $-9.9 \pm 12.7$ \\
\hline Post-2 & $3.7 \pm 1.4$ & $-13.3 \pm 26.4$ & $4.4 \pm 1.8$ & $2.7 \pm 42.5$ \\
\hline
\end{tabular}

Only six subjects finished post-2 in S-A condition

$T A G$ triacylglycerol, $T C$ total cholesterol, $H D L$ high-density lipoprotein, $L D L$ low-density lipoprotein, $T C /$ $H D L$ atherogenic index

a Difference between S-A and A-S conditions

b Statistical difference from delta post-1 A-S

c Statistical difference from delta post-2 S-A 
demonstrated that there are no differences in lipid metabolism responses relative to the execution order of HIIT plus strength performance in concurrent exercise sessions in physically active men.

Both endurance and strength exercises are well established as positive modulators of lipoprotein profiles $[19,20]$. Lira et al. [9] demonstrated that strength exercise performed at $75 \%$ of maximum RM was effective at reducing TAG when compared to other groups $(50,90$, and $110 \%$ RM). HDL concentrations were significantly greater in the 50 and $70 \%$ RM groups when compared to the $110 \%$ RM. Moreover, the $50 \%$ RM group presented a greater decrease in LDL concentration when compared to the $110 \%$.

Hill et al. [21] found an increase in HDL concentrations only after moderate acute resistance exercise ( 3 sets of 10 repetitions at $10 \mathrm{RM}$ ); however, low-intensity resistance exercise did not result in the same (3 sets of 20 repetitions at $50 \% 10 \mathrm{RM})$. Wallace et al. [22] found high-volume moderate-intensity strength exercise (73\% RM) increased both HDL-c and HDL3-c concentrations by $10 \%$ when compared to low-volume, high-intensity ( $92 \% \mathrm{RM})$ exercise. Furthermore, only at the high-volume exercise level was TAG concentration lower $24 \mathrm{~h}$ post-exercise. However, both studies performed exercises for different muscle groups, as opposed to the present study, which used only the half-squat exercise, which may have been a reason for no statistical difference over time.

The anti-atherogenic effects of continuous, prolonged endurance exercise have been widely documented, particularly through the modulation of the lipid profile $[10,19,20,23]$. However, the literature is limited regarding studies that have examined the anti-atherogenic effects of HIIE. Interestingly, the lowering of LDL-c concentrations seems to be mediated by HIIE, since after strength exercise, its concentrations are decreased, and at the end of the run exercise, regardless of the sequence (A-S or S-A), the concentrations decreased. Lira et al. [24] showed that even a single session of high-intensity exercise was able to lower both LDL and TC immediately and $1 \mathrm{~h}$ after exercise. Whyte et al. [25] showed that only six HIIE sessions lowered fasting glucose and increased insulin sensitivity, and also resulted in mild lipoprotein improvements.

Furthermore, regular high-intensity exercise also promotes positive changes in lipoprotein profiles. For example, endurance athletes presented lower LDL-c concentrations than their sedentary peers $[26,27]$. Such outcomes occur, because athletes have a higher free-cholesterol efflux from tissue to HDL-c, which is mediated by lecithin-cholesterol acyltransferase (LCAT), an enzyme responsible for reversing cholesterol transport [28]. In fact, regardless of physical fitness, a single session of HIIE is able to increase the reverse cholesterol pathway [29]. For acute adaptations of strength exercise, as aforementioned, the decrease in VLDL-TAG concentration after regular HIIE was related more to the decrease in its production in the liver than its plasmatic clearance [30].

Concurrent exercise is well established as a powerful promoter of energetic spending [31, 32]. In fact, several factors are determinants of exercise-induced anti-atherogenic profiles, of which energy expenditure is the most important $[19,20]$. Authors point out that there is a threshold (greater than $800 \mathrm{kcal}$ ) before anti-atherogenic benefits can be observed $[19,20]$. Thus, strategies that increase energy expenditure in exercise, such as concurrent exercise, may be a good way to improve lipoprotein profiles. Accordingly, greater energy expenditure requires specific adaptations, especially as regard VLDL secretion [20]. One of the probable adaptations is related to the increase in adiposetissue fatty acid release and its oxidation in skeletal muscle [33], which is promoted through lipoprotein lipase and the carnitine palmitoyltransferase system [34].

To the best of our knowledge, we did not find studies aimed at verifying the differences in adaptations between the sequence of concurrent exercises and lipoprotein profiles, nor did we find studies that used a running exercise as the HIIE. One study carried out by Silvestre et al. [35] aimed to evaluate lipid and metabolic profiles after a session of acute combined exercise, in which strength exercise was composed of three sets of ten repetitions of the wholebody exercise at $95 \%$ of $10 \mathrm{RM}$ followed by $30 \mathrm{~min}$ of treadmill running exercise $(\sim 450 \mathrm{kcal})$. The authors found that the previous combined exercise, performed 4 and $16 \mathrm{~h}$ before blood analysis, was related to increased TAG clearance. Moreover, the same pattern was also found in insulin levels, in which exercise improved insulin sensitivity.

The present study demonstrated that, despite the existence of differences between conditions, there was no effect of exercise execution order over time in the variables evaluated. However, when considering the delta values, there were statistical differences over time. When strength exercise is performed prior to HIIE, the lipid profile behaviour differs over the time of the exercise session with delta of TAG, TC, and LDL showing an interaction effect between delta-1 and delta-2 S-A. It is noteworthy that the S-A delta-2 was negative. This result could suggest that HIIE performed after strength exercise anticipates the return of lipid fractions to baseline values. In addition, TAG presented an interaction effect between delta-1 S-A and delta-1 A-S, possibly suggesting that in the S-A sequence TAG level, behaviour tends to augment, while at the same A-S moment, there was no percentage change. However, more consistent studies are necessary to clarify this hypothesis. 
Despite these results being of great relevance, we should mention that the lack of long-term observation of the lipoprotein profiles and the energy expenditure evaluation, as well as the low number of subjects, is limitations that should indicate that caution is needed when generalizing the conclusions found here. Furthermore, we did not collect blood samples 30 and $60 \mathrm{~min}$ after the end of the exercises, which prevented us from analysing the lipid responses at these moments. In addition, another limitation of the present study is the drop out of participants that could not tolerate performing the $5-\mathrm{km}$ run at high intensity after a strength training session. Therefore, it would be interesting to test the effects on the lipid profile with a more tolerable exercise session.

In summary, the present study suggests that there are no differences between the order of acute high-intensity intermittent run plus strength exercises regarding modulation of the lipoprotein profile in healthy, physically active men.

Acknowledgments Fabio Santos Lira thanks Fapesp for their support (2013/25310-2)

\section{Compliance with ethical standards}

Conflict of interest The authors declare that they have no conflict of interest.

Ethical approval All procedures performed in studies involving human participants were in accordance with the ethical standards of the institutional and/or national research committee and with the 1964 Helsinki declaration and its later amendments or comparable ethical standards.

Informed consent Informed consent was obtained from all individual participants included in the study.

\section{References}

1. Ekelund U, Ward HA, Norat T, Luan J, May AM, Weiderpass E, Sharp SJ, Overvad K, Ostergaard JN, Tjonneland A, Johnsen NF, Mesrine S, Fournier A, Fagherazzi G, Trichopoulou A et al (2015) Physical activity and all-cause mortality across levels of overall and abdominal adiposity in European men and women: the European Prospective Investigation into Cancer and Nutrition Study (EPIC). Am J Clin Nutr 101(3):613-621. doi:10.3945/ajcn. 114.100065

2. Rosamond W, Flegal K, Furie K, Go A, Greenlund K, Haase N, Hailpern SM, Ho M, Howard V, Kissela B, Kittner S, LloydJones D, McDermott M, Meigs J, Moy C et al (2008) Heart disease and stroke statistics-2008 update: a report from the American Heart Association Statistics Committee and Stroke Statistics Subcommittee. Circulation 117(4):e25-e146. doi:10. 1161/CIRCULATIONAHA.107.187998

3. Haskell WL, Lee IM, Pate RR, Powell KE, Blair SN, Franklin BA, Macera CA, Heath GW, Thompson PD, Bauman A (2007) Physical activity and public health: updated recommendation for adults from the American College of Sports Medicine and the
American Heart Association. Med Sci Sports Exerc 39(8):1423-1434. doi:10.1249/mss.0b013e3180616b27

4. Durstine JL, Grandjean PW, Cox CA, Thompson PD (2002) Lipids, lipoproteins, and exercise. J Cardpulm Rehabil 22(6):385-398

5. Tsekouras YE, Yanni AE, Bougatsas D, Kavouras SA, Sidossis LS (2007) A single bout of brisk walking increases basal very low-density lipoprotein triacylglycerol clearance in young men. Metab Clin Exp 56(8):1037-1043. doi:10.1016/j.metabol.2007. 03.012

6. Burgomaster KA, Hughes SC, Heigenhauser GJ, Bradwell SN, Gibala MJ (2005) Six sessions of sprint interval training increases muscle oxidative potential and cycle endurance capacity in humans. J Appl Physiol 98(6):1985-1990. doi:10.1152/japplphy siol.01095.2004

7. Gibala MJ, Little JP, van Essen M, Wilkin GP, Burgomaster KA, Safdar A, Raha S, Tarnopolsky MA (2006) Short-term sprint interval versus traditional endurance training: similar initial adaptations in human skeletal muscle and exercise performance. J physiol 575(Pt 3):901-911. doi:10.1113/jphysiol.2006.112094

8. Garber CE, Blissmer B, Deschenes, Franklin BA, Lamonte MJ, Lee IM, Nieman DC, Swain DP, American College of Sports M (2011) American College of Sports Medicine position stand. Quantity and quality of exercise for developing and maintaining cardiorespiratory, musculoskeletal, and neuromotor fitness in apparently healthy adults: guidance for prescribing exercise. Med Sci Sports Exerc 43(7):1334-1359. doi:10.1249/MSS. Ob013e318213fefb

9. Lira FS, Yamashita AS, Uchida MC, Zanchi NE, Gualano B, Martins E Jr, Caperuto EC, Seelaender M (2010) Low and moderate, rather than high intensity strength exercise induces benefit regarding plasma lipid profile. Diabetol Metab Syndr 2:31. doi:10.1186/1758-5996-2-31

10. Tambalis K, Panagiotakos DB, Kavouras SA, Sidossis LS (2009) Responses of blood lipids to aerobic, resistance, and combined aerobic with resistance exercise training: a systematic review of current evidence. Angiology 60(5):614-632. doi:10.1177/ 0003319708324927

11. Cortez-Cooper MY, DeVan AE, Anton MM, Farrar RP, Beckwith KA, Todd JS, Tanaka H (2005) Effects of high intensity resistance training on arterial stiffness and wave reflection in women*. Am J Hypertens 18(7):930-934. doi:10.1016/j.amjhyper.2005.01. 008

12. Ghahramanloo E, Midgley AW, Bentley DJ (2009) The effect of concurrent training on blood lipid profile and anthropometrical characteristics of previously untrained men. J Phys Act Health 6(6):760-766

13. Kelley GA, Kelley KS, Tran ZV (2004) Aerobic exercise and lipids and lipoproteins in women: a meta-analysis of randomized controlled trials. J Women's Health 13(10):1148-1164. doi:10. 1089/jwh.2004.13.1148

14. Lira FS, Neto JC, Seelaender M (2014) Exercise training as treatment in cancer cachexia. Appl Physiol Nutr Metabol 39(6):679-686. doi:10.1139/apnm-2013-0554

15. Leveritt M, Abernethy PJ (1999) Acute effects of high-intensity endurance exercise on subsequent resistance activity. J Strength Cond Res 13(1):47-51

16. Brown LE, Weir JP (2001) ASEP procedures recommendation I: accurate assessment of muscular strength and power. Prof Exerc Physiol 4(3):1-21. https://www.asep.org/asep/asep/Brown2.pdf

17. Cohen J (1988) Statistical power analysis for the behavioural sciences. Lawrence Earlbaum Associates, Hillsdale

18. Hopkins W (2008) A scale of magnitudes for effect statistics, 2002. http://sportsci.org/resource/stats/effectmag.html. Accessed 10 Sept 2015 
19. Lira FS, Carnevali LC Jr, Zanchi NE, Santos RV, Lavoie JM, Seelaender M (2012) Exercise intensity modulation of hepatic lipid metabolism. J Nutr Metab 2012:809576. doi:10.1155/2012/ 809576

20. Magkos F (2009) Basal very low-density lipoprotein metabolism in response to exercise: mechanisms of hypotriacylglycerolemia. Prog Lipid Res 48(3-4):171-190. doi:10.1016/j.plipres.2009.02. 003

21. Hill S, Bermingham MA, Knight PK (2005) Lipid metabolism in young men after acute resistance exercise at two different intensities. J Sci Med Sport/Sports Med Aust 8(4):441-445

22. Wallace MB, Moffatt RJ, Haymes EM, Green NR (1991) Acute effects of resistance exercise on parameters of lipoprotein metabolism. Med Sci Sports Exerc 23(2):199-204

23. Magkos F, Wright DC, Patterson BW, Mohammed BS, Mittendorfer B (2006) Lipid metabolism response to a single, prolonged bout of endurance exercise in healthy young men. Am J Physiol Endocrinol Metab 290(2):E355-E362. doi:10.1152/ajpendo. 00259.2005

24. Lira FS, Zanchi NE, Lima-Silva AE, Pires FO, Bertuzzi RC, Santos RV, Caperuto EC, Kiss MA, Seelaender M (2009) Acute high-intensity exercise with low energy expenditure reduced LDL-c and total cholesterol in men. Eur J Appl Physiol 107(2):203-210. doi:10.1007/s00421-009-1115-5

25. Whyte LJ, Gill JM, Cathcart AJ (2010) Effect of 2 weeks of sprint interval training on health-related outcomes in sedentary overweight/obese men. Metab Clin Exp 59(10):1421-1428. doi:10.1016/j.metabol.2010.01.002

26. Brites F, Verona J, De Geitere C, Fruchart JC, Castro G, Wikinski R (2004) Enhanced cholesterol efflux promotion in well-trained soccer players. Metab Clin Exp 53(10):1262-1267. doi:10.1016/j. metabol.2004.05.002

27. Gupta AK, Ross EA, Myers JN, Kashyap ML (1993) Increased reverse cholesterol transport in athletes. Metab Clin Exp 42(6):684-690
28. Fielding CJ, Fielding PE (1995) Molecular physiology of reverse cholesterol transport. J Lipid Res 36(2):211-228

29. Frey I, Baumstark MW, Berg A, Keul J (1991) Influence of acute maximal exercise on lecithin:cholesterol acyltransferase activity in healthy adults of differing aerobic performance. Eur J Appl Physiol 62(1):31-35

30. Tsekouras YE, Magkos F, Prentzas KI, Basioukas KN, Matsama SG, Yanni AE, Kavouras SA, Sidossis LS (2009) A single bout of whole-body resistance exercise augments basal VLDL-triacylglycerol removal from plasma in healthy untrained men. Clin Sci 116(2):147-156. doi:10.1042/CS20080078

31. Lira FS, de Oliveira RSF, Julio UF, Franchini E (2007) Strength and aerobic post-exercises oxygen consumption: effect of the order of performance. Rev Bras Med Esporte (in its portuguese form). doi:10.1590/S1517-86922007000600009

32. Panissa VLG, Bertuzzi RCdM, Lira FSd, Júlio UF, Franchini E (2009) Concurrent exercise: analysis of the acute effect of the performance order on the total energy expenditure. Revista Brasileira De Medicina Do Esporte 15(2):127-131. doi:10.1590/ S1517-86922009000200009

33. Gibala MJ, Little JP, Macdonald MJ, Hawley JA (2012) Physiological adaptations to low-volume, high-intensity interval training in health and disease. J Physiol 590(Pt 5):1077-1084. doi:10.1113/jphysiol.2011.224725

34. Fisher RM, Coppack SW, Humphreys SM, Gibbons GF, Frayn KN (1995) Human triacylglycerol-rich lipoprotein subfractions as substrates for lipoprotein lipase. Clin Chim Acta 236(1):7-17. doi:10.1016/0009-8981(95)06032-3

35. Silvestre R, Kraemer WJ, Quann EE, Seip RL, Maresh CM, Vingren JL, Hatfield DL, Volek JS (2008) Effects of exercise at different times on postprandial lipemia and endothelial function. Med Sci Sports Exerc 40(2):264-274. doi:10.1249/mss. Ob013e31815c485a 